\title{
Managing grey mould on raspberry grown under protection without use of fungicides during flowering and fruiting
}

\author{
Tim O’Neill • Erika Wedgwood • Angela M. Berrie • \\ Janet Allen • Xiangming Xu
}

Accepted: 17 October 2011 / Published online: 17 November 2011

(C) INRA and Springer-Verlag, France 2011

\begin{abstract}
Grey mould, caused by Botrytis cinerea, is one of the most important diseases of raspberry. In the UK, the majority of raspberry production has recently switched to cropping under polythene tunnels but without corresponding changes in managing grey mould despite the fact that the risk of grey mould is greatly reduced under protection. On average, two to four applications of fungicides are specifically targeted at $B$. cinerea during flowering and fruiting, leading to more than $50 \%$ fruit containing detectable amount of fungicide residues. Based on new findings on epidemiology of this disease under protection, we have developed a new integrated pest and disease management strategy to manage grey mould where fungicides are not applied during the flowering and fruiting period, but rapid post-harvest cooling and cold storage is used to delay the onset of fungal rotting. This new strategy was evaluated over 2 years at two commercial sites. Our main findings are: (1) The strategy produced a marketable yield as high as the conventional programme and resulted in comparable levels of grey mould and (2) rapid post-harvest cooling and subsequent storage at $4-5^{\circ} \mathrm{C}$ or below generally led to a reduced level of fungal rotting of fruit 9 days after harvest, which is comparable to the average maximum post-harvest period before consumption. Thus, we concluded that this new strategy can be adopted for managing grey mould on raspberry grown under
\end{abstract}

T. O'Neill $\cdot$ E. Wedgwood $\cdot$ J. Allen

ADAS Boxworth,

Battlegate Road, Boxworth,

Cambridge CB23 4NN, UK

A. M. Berrie $\cdot X . X u(\bowtie)$

East Malling Research,

New Road, East Malling,

West Malling ME19 6BJ, UK

e-mail: xiangming.xu@emr.ac.uk protection. Adoption of this strategy will not only reduce the fungicide input but also lead to production of fruit with zero fungicide residues.

Keywords Botrytis cinerea $\cdot$ Raspberry $\cdot$ Grey mould $\cdot$ Cold storage $\cdot$ Zero residues

\section{Introduction}

Raspberry fruit are very susceptible to Botrytis cinerea Pers. ex Fr. resulting in serious yield losses, especially postharvest as the result of latent infections developing into visual rots (McNicol et al. 1985), with an average loss of near $50 \%$ after 7 days of storage at room temperature (Xu et al. 2011) (Fig. 1). The fungus can also cause disease on raspberry canes, namely cane botrytis, leading to nodal lesions, impaired axillary growth and lateral shoot failure in spring (Williamson and Jennings 1986). Prominent sclerotia form beneath the epidermis of canes during winter and erupt in spring. During periods of high humidity, these sclerotia become covered with conidia, an important inoculum source for infection of flowers (Jennings and Carmichael 1975). Development of B. cinerea in open-field raspberries is highly dependent on initial inoculum and specific environment conditions (Jarvis 1962a, b, 1964; Harrison and Williamson 1986). Research on other crops has shown that grey mould can be managed effectively by targeting these two factors (Xu et al. 2000; Bielenin 2002; O'Neill et al. 2002). In field crops of raspberry, correlations were found between post-harvest grey mould on raspberry fruit and high relative humidity in the 5-day period before picking and rainfall during picking (Jarvis 1964).

In the UK, raspberry is now mostly grown under protection, usually Spanish tunnels, to extend the production 
Fig. 1 a Healthy raspberry fruit, b pre-harvest grey mould and $\mathbf{c}$ post-harvest fruit rotting
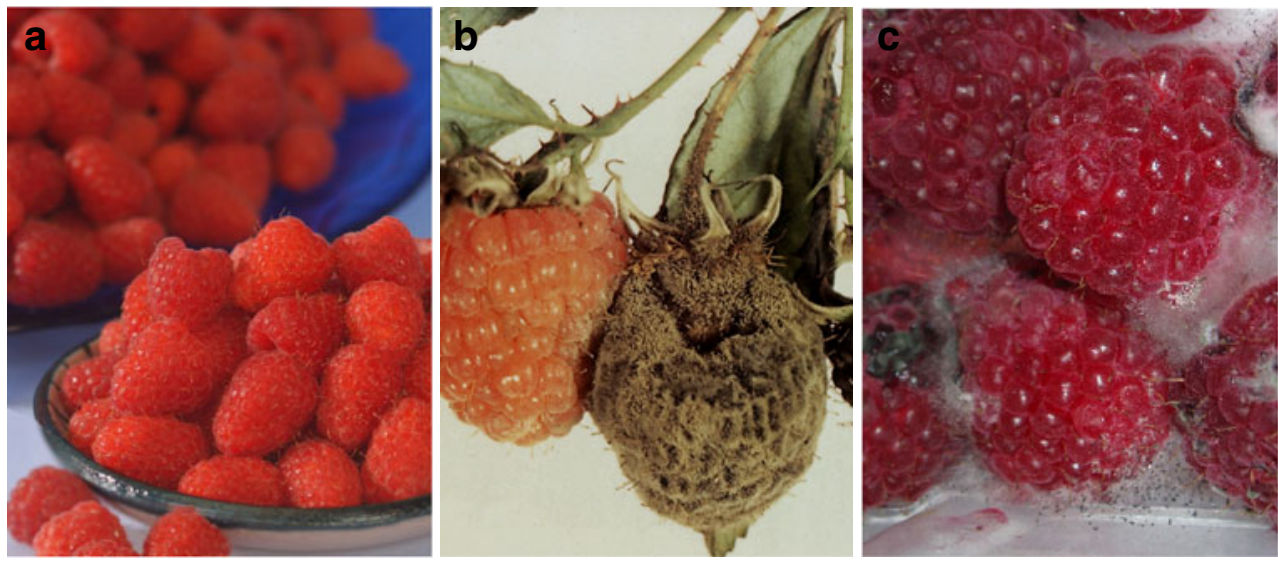

season and to protect fruit from rain during the cropping period. It is expected that the risk of grey mould of raspberry is greatly reduced under protection, compared with open-field production, as observed on other fruit crops (Xiao et al. 2001; Creemers et al. 2006; Evenhuis and Wanten 2006) because of reduced humidity and protection of flowers and fruit from rainfall. In the absence of soundly based guidance on raspberry grey mould under protection, growers still apply fungicides (usually two to four applications) to control $B$. cinerea during flowering and fruiting. This scheduled application of fungicides to control grey mould may not be necessary, and it also leads to detectable amounts of residues on fruit-retail surveillance has demonstrated that more than $50 \%$ of UK produced fruit contains fungicide residues. At present in the UK, fruit are generally cooled and held at $4-5^{\circ} \mathrm{C}$ for up to 3 days from harvest and then in temperatures up to about $16^{\circ} \mathrm{C}$ during transport and shop display until they are sold. Cold storage can delay the onset of grey mould symptom development, compared to ambient conditions (McNicol et al. 1990; Ellis et al. 2008).

Another possible avenue to reduce the level of grey mould is through canopy manipulation by cultural practices, which can significantly alter microclimatic conditions, particularly increasing air movement. Narrower spacing led to higher incidence of B. cinerea on strawberry fruit but higher yield (Legard et al. 2000). However, canopy manipulation has recently been shown not to result in any appreciable reductions in the incidence of $B$. cinerea infection of raspberry fruit under protection (O'Neill et al. 2009), in contrast to results obtained on bunch rot of grape caused by B. cinerea (Zoecklein et al. 1992; English et al. 1993; Duncan et al. 1995).

We have recently obtained several key findings on the epidemiology of grey mould on raspberry grown under protection (Xu et al. 2011): (1) The level of infection of raspberry flowers is still high under protection; (2) there is still a considerable level of latent infection by $B$. cinerea on fruit under protection; (3) the level of ripe fruit with visual symptoms at harvest was low, usually close to zero and (4) nearly all fruits from both fungicide sprayed and unsprayed crops were colonised by several fungi, including $B$. cinerea, within 7 days of harvest when stored at ambient conditions. Based on these results, we developed a new strategy to manage grey mould on raspberry grown under protection, consisting of two components (pre-harvest and postharvest). During pre-harvest, fungicides are only applied outside of the flowering and fruiting period to provide adequate control of other diseases (including cane botrytis). In the post-harvest phase, rapid cooling and subsequent prolonged cold is used to prevent grey mould and other fungal rots from becoming visible before consumption (normally the time from harvest to consumption for both strawberry and raspberry is less than 7 days).

This paper reports the results of seven trials in commercial crops to evaluate this strategy in terms of the incidence of grey mould as well as commercial production. Specifically, we aimed to determine: (1) whether postharvest rapid cooling delays the onset of fungal rot symptoms and (2) whether the new management strategy results in as good control of grey mould (and other fungal rots) as the conventional management programme. Additionally, in two of the trials, the effect of growing under protection compared with open field and applying a twospray fungicide programme during flowering and fruiting were examined for their influence on post-harvest fruit grey mould. This work formed part of a larger project to devise an integrated pest and disease management (IPDM) strategy that provides effective control of pests and diseases in protected raspberry while minimising risk of detectable pesticide residues in fruit.

\section{Materials and methods}

2.1 Effect of cold storage on the incidence of $B$. cinerea and other fungi on raspberry fruit post-harvest

Three experiments were carried out to determine the effect of rapid post-harvest cold/cool storage treatments on the 
incidence of grey mould and other types of fungal rotting on fruit. These three experiments represent a logical progression of field trials over the 3 years. Two experiments were conducted in 2007 and 2008 at a commercial farm near Cambridge, UK, and the third experiment was conducted at a commercial site in 2010 in Kent, UK.

\subsubsection{7 experiment}

Three storage regimes were compared: (1) cold conditions4 days in a grower's cold store at $4.5^{\circ} \mathrm{C},(2)$ standard storage2 days in the same cold store at $4.5^{\circ} \mathrm{C}$ before removal to a cool shelf at around $12^{\circ} \mathrm{C}$ in the packing area (to represent coolchain transport and retail display) and (3) ambient conditions. In addition to the storage conditions, three sources of fruit were used to have a range of grey mould incidence: (1) covered and unsprayed, (2) open and unsprayed and (3) covered and sprayed. The first two sources were from the same Spanish tunnel of three rows of cv. Glen Ample not sprayed with fungicide during flowering, with part of the tunnel not polythene-covered. The third source was an adjacent commercially sprayed tunnel of the same variety which received two applications of Teldor WP $(50 \%$ fenhexamid) at $1.5 \mathrm{~kg} / \mathrm{ha}$ during flowering. Within each source, firm ripe fruits were picked in the morning of 16 July from three plots, each $3 \mathrm{~m}$ long, spaced along the central row.

A total of 150 fruit was picked from all heights within each plot and placed directly into punnets, with 25 fruit in a single layer per punnet. Punnets of fruit that required cold storage were transferred to the appropriate storage place within $2 \mathrm{~h}$ of picking. Two punnets from each plot were randomly allocated to each of the three storage regimes. Ventilated punnet lids were fitted to the punnets at the start of storage. The pairs of punnets from the same plot of each crop source were placed together in a tray, with the three replicates of trays being stacked. For the six punnets allocated to the ambient condition, the fruit were transferred to multicell trays (one fruit per cell), sealed in a transparent plastic bag and incubated in the laboratory out of direct sunlight (temperatures ranged from a daily average of $17^{\circ} \mathrm{C}$ to $20^{\circ} \mathrm{C}$ ). These conditions ensured that all moulds became easily visible without spreading between fruit. After 4 days, the punnets were collected from the cold and cool storage areas and placed in the same room as the multicell trays for a further 5 days. The fruit were assessed without touching them at 2, 4, 7 and 9 days after picking. Fungal growth characteristic of Botrytis, Penicillium and Mucor was recorded.

\subsubsection{8 experiment}

Following the results from the 2007 experiment, the 2008 experiment focused on the effect of rapid cooling to $1-2^{\circ} \mathrm{C}$ immediately after harvest. There were five post-harvest storage regimes (Table 1). As in 2007, three sources of fruit were used, with three replicate plots in each source. The experiment was done in the same field as in 2007 but in different tunnels. For the commercial crop, Teldor WP (50\% fenhexamid) was applied at first open flowers and 2 weeks later (50\% flowering) to control grey mould. Flowers were tagged with coloured wool three times a week just as they were starting to open and become susceptible to $B$. cinerea infection, and the relevant colour noted when the fruit was picked; this allowed us to examine whether fruit developing from flowers open at the time of spray treatment differed in the incidence of post-harvest fruit rots from those opening at other times.

For the unsprayed uncovered crop, marketable ripe fruit were picked on 23 June and 7 July; for the other two sources of crop, fruit were picked on 23 June, 30 June, 7 July and 14 July. Fruit were picked fewer times in the uncovered because the comparison between protected and uncovered crops was not essential. At each pick, 25 fruit were picked into each of two punnets per replicate plot for each storage treatment and taken to their storage areas within $2 \mathrm{~h}$ of picking. Punnets for each storage treatment were kept in cardboard produce trays and moved between conditions at the intervals shown in Table 1. Lids were put on once on a shelf either in the cool packhouse area (to mimic transport and shop display storage areas) or in an office (mimicking home storage). A data logger was kept in each storage area to monitor temperature and relative humidity. Disease assessments were carried out at intervals without handling by looking through the clear transparent plastic sides of the punnet and over the top of the fruit. The number of fruit with Botrytis and other fungi (including Fusarium, Penicillium and Cladosporium) were counted. Fruit was assessed for fungal growth at 2, 4, 7 and 9 days after picking.

\subsubsection{0 experiment}

Following the 2008 experiment, the experiment in 2010 compared two storage regimes to determine whether

Table 1 Details of storage treatments evaluated in 2008 showing the number of days fruit was held in each temperature condition

\begin{tabular}{lcccc}
\hline Treatment & $\begin{array}{l}\text { Rapid heat } \\
\text { removal } \\
\left(2^{\circ} \mathrm{C}\right)^{\mathrm{a}}\end{array}$ & $\begin{array}{l}\text { Cold } \\
\text { storage } \\
\left(3^{\circ} \mathrm{C}\right)\end{array}$ & $\begin{array}{l}\text { Transport+ } \\
\text { final display } \\
\left(17^{\circ} \mathrm{C}\right)\end{array}$ & $\begin{array}{l}\text { Home } \\
\text { storage } \\
\left(22^{\circ} \mathrm{C}\right)\end{array}$ \\
\hline Ambient control & 0 & 0 & 0 & 9 \\
Good practice & 0 & 2 & 2 & 5 \\
Rapid heat removal & 1 & 1 & 2 & 5 \\
No cool chain & 1 & 1 & 0 & 7 \\
Prolonged cold storage & 1 & 3 & 3 & 2 \\
\hline
\end{tabular}

${ }^{\mathrm{a}}$ Cold store temperature during forced air cooling 
prolonged cold storage at $2-3^{\circ} \mathrm{C}$ following the initial rapid cooling to remove field heat could further delay onset of fungal rotting, compared to cold storage at $4-5^{\circ} \mathrm{C}$ (Table 2); these two storage regimes were the same as those used in the IPDM trial (see below). At each pick (on 28 July, 04 August, 11 August and 18 August), about 25-40 marketable ripe fruit were picked into each of ten punnets per regime from an unsprayed tunnel crop of cv. Octavia and taken to their storage areas within $2 \mathrm{~h}$ of picking. Punnets for each storage treatment were kept in plastic produce trays to move between conditions and were assessed for fruit rots at days 6 and 8 after picking.

\subsubsection{Statistical analysis}

Linear mixed models were applied to the logit-transformed proportion of healthy fruit and fruit with grey mould at each assessment time. In 2007 and 2008, storage regimes, crop sources and assessment time were treated as fixed effects, and a power model was used to model the temporal correlation among the four assessment times. In addition, different picks were treated as random effects in 2008. For the 2010 trial, a simple generalised linear model was applied to the data with different picks treated as replicates, assuming a binomial distribution for the proportion of fruit with fungal rot.

2.2 Field evaluation of the new strategy for managing grey mould

\subsubsection{Plantations and treatments}

Evaluation of the new management strategy was done on two commercial farms per year in 2009 and 2010, one in Kent and the other in Cambridgeshire. The same tunnels were allocated to the same treatments in both years. There were four treatments: two management strategies (conventional and the new IPDM strategy) with two post-harvest storage regimes (Table 2). In the conventional strategy, scheduled fungicides were applied during the flower/ fruiting period, whereas in the new IPDM strategy, fungicides were not applied during the flower/fruiting period. At each site, a single tunnel was randomly allocated to one of the two management treatments; there was thus no replication of the management strategy at a single site because of the high potential cost of any crop compensation with a large crop area.

At the Kent site, cv. Tulameen was planted in spring 2005 with a row spacing of $2.2 \mathrm{~m}$; there were about eight fruiting canes per metre length of the row (on average three canes per stool). The IPDM tunnel was approximately $180 \mathrm{~m}$ long with three rows of plants, and the tunnel for the conventional programme was approximately $90 \mathrm{~m}$ long. The crop was covered a week before bud break in both years. At the Cambridgeshire site, two tunnels (approximately $80-90 \mathrm{~m}$ long) of three rows of cv. Octavia with eight fruiting canes per metre (planted in 2005) were used. The crop was covered after bud break about 4 weeks before flowering in both years. At both sites, for the conventional treatment, two fungicide sprays were applied to control grey mould timed at $10-15 \%$ (Teldor WP $(50 \%$ fenhexamid) at $1.5 \mathrm{~kg} / \mathrm{ha}$ in 2009 and Switch (cyprodinil) at $1.0 \mathrm{~kg} / \mathrm{ha}$ in 2010 ) and $50 \%$ (Scala (pyrimethanil) at $2.0 \mathrm{~L} /$ ha in 2009 and Signum (boscalid + pyraclostrobin) at $1.8 \mathrm{~kg} / \mathrm{ha}$ in 2010) flowering.

Fruit were randomly picked from each treatment tunnel four times within each year, approximately evenly spread over the entire harvest period of 7-8 weeks, starting from the second week of harvesting. At each pick, six punnets of fruit (each with approximately 25 fruit) were randomly picked from different areas in the tunnel for each combination of management strategy and storage regime at each site. At each sampling time, ripe fruit in the crop was assessed for visual grey mould symptoms by estimating the proportion of fruit visibly affected at seven positions per replicate block. Fruit were picked by the grower's staff into standard punnets and put into cold storage within $2 \mathrm{~h}$. Punnet lids were fitted on day 2, after field heat removal (Table 2).

\subsubsection{Assessment}

Fruit was assessed for fungal rots and other damage on days 6 and 8 . The day 6 score was made through the punnet walls, scoring the number of fruit with and without any obvious mould or rot. It was not possible to identify the fungi at this stage. The day 8 assessment required the fruit to be lifted out one at a time with

Table 2 Two storage treatments applied to fruit from commercial crops of raspberry grown under both conventional and integrated programmes at Cambridge and Kent, UK in 2009 and 2010 to compare the effect of storage conditions on development of fruit rot

\begin{tabular}{llccccccc}
\hline & Day 1 & Day 2 & Day 3 & Day 4 & Day 5 & Day 6 & Day 7 & Day 8 \\
\hline Storage Regime & Rapid heat & \multicolumn{2}{c}{ Cold storage } & \multicolumn{2}{c}{$\begin{array}{c}\text { Simulated transport } \\
\text { on farm }\end{array}$} & \multicolumn{2}{c}{ and shop display } & Simulated storage at home (not refrigerated) \\
Cold, ${ }^{\circ} \mathrm{C}$ & $1-2$ & $2-3$ & $2-3$ & 16 & 16 & 20 (Assess) & 20 & (Assess) \\
Normal, ${ }^{\circ} \mathrm{C}$ & $1-2$ & $4-5$ & $4-5$ & 16 & 16 & 20 (Assess) & 20 & (Assess) \\
\hline
\end{tabular}


minimal handling. The total number of fruit per punnet with obvious mould or rot was counted. On several occasions, a further assessment was also made if there was insufficient amount of rot development on day 8. In addition, the discarded fruit from commercial field picking was also held in a refrigerator for weekly assessment of fungal rotting. In the final assessment, fruit was classified as healthy (without apparent fungal rotting), infected by fungi (including B. cinerea, Fusarium, Mucor etc.), or by bacteria, or damaged by other agents. Some berries had more than one fungus present, and these were scored under each category. Overgrowth of fungus which was clearly from a neighbouring fruit was excluded, as the records were to determine the number of fungal species which had grown out of the fruit, not the subsequent post-harvest spread. In addition, all marketable and waste fruit from each experimental tunnel were weighed and used to estimate yield and crop losses. Both tunnel and within-punnet (i.e. post-harvest) temperature and humidity were recorded with data loggers during the entire experimental periods.

\subsubsection{Statistical data analysis}

The main objective was to determine whether the management strategies and cold storage regimes significantly affected the proportion of healthy fruit and those with grey mould. Thus, a generalised linear mixed model was applied to the data summarised over all picks within each year. A binomial distribution was assumed for the incidence of healthy fruit and those with grey mould (or other damaging agents); cold regime and management strategy were treated as fixed effects whereas the four combinations of year and site were treated as random effects. Wald tests were used to determine the significance of treatment effects. The analysis was only applied to the day 8 assessment because of very low numbers of fruit with fungal rot or other damage on day 6. All statistical analyses were conducted using Genstat (Payne 2006).

\section{Results and discussion}

In all experiments, some fruit were colonised by more than one fungus.

3.1 Effect of cold storage on the incidence of grey mould on fruit post-harvest

\section{1 .12007}

In 2007, there was either no or a trace level of visible growth of $B$. cinerea on the fruit up to 7 days after harvest following all storage treatments (Fig. 2a, b). The incidence of $B$. cinerea increased steeply from 7 to 9 days after storage, especially for the fruit from the outside crop and for fruit stored at ambient conditions (Fig. 2a, b): More than $31 \%$ fruit had developed grey mould on day 9 . Despite the low level of grey mould in early assessment times, there was a significant reduction in the proportion of healthy fruit even on day 4 following the ambient storage conditions and nearly $80 \%$ of fruit had botrytis growth by day 7 following this storage (Fig. 2c). The majority of fruit loss was from the outside crop (Fig. 2d).

There were no significant interactions among the treatment factors, but their main effects were all significant $(P<0.001)$ for incidences of grey mould and healthy fruit. Most treatment differences were due to the differences observed 9 days after storage (Fig. 2). Cold storage treatment led to a significantly greater proportion of healthy fruit than the standard cool storage, which in turn was greater than when held at ambient. The proportion of fruit with grey mould was similar for the two non-ambient conditions, which was significantly less than under the ambient regime. Overall, fruit from outside had the lowest proportion of healthy fruit compared with fruit from the protected crop; the opposite was true for the proportion of fruit with grey mould.

Apart from B. cinerea, Penicillium sp. was another important rotting agent but only seen 7 days after picking. Storage treatment significantly influenced the incidence of affected fruit $(P<0.01)$, with more fruit showing Penicillium sp. after storage at ambient conditions throughout. Mucor sp. was also first seen following 7 days storage but at a low incidence. Initial cold storage for 4 days nearly completely inhibited the appearance of Mucor for 7 days after picking.

\section{1 .22008}

In 2008 , the temperature in the tray stack in the field heat removal area ranged from $4.8^{\circ} \mathrm{C}$ to $7.5^{\circ} \mathrm{C}$ (mean $6.5^{\circ} \mathrm{C}$ ) although within the forced air stream the air temperature was $2^{\circ} \mathrm{C}$. Relative humidity was always above $80 \%$. Temperature inside the shop cold store ranged from $1.6^{\circ} \mathrm{C}$ to $3.9^{\circ} \mathrm{C}$ (mean $3.3^{\circ} \mathrm{C}$ ) whereas the shelf life room varied between $16^{\circ} \mathrm{C}$ and $18^{\circ} \mathrm{C}$ with a mean of $17^{\circ} \mathrm{C}$ (higher than the $12^{\circ} \mathrm{C}$ planned). Final storage was at a mean room temperature of $22.7^{\circ} \mathrm{C}$ with a range of $18^{\circ} \mathrm{C}$ to $28^{\circ} \mathrm{C}$.

Overall, the proportion of fruit with grey mould was significantly affected by storage regime, crop source and assessment time as well as by the interactions of assessment time with cold storage regime and crop source (Fig. 3). The effect of storage treatment can be seen after 2 days whereas the effect of crop source showed up relatively late. The treatment differences were consistent among the four picks. 
Fig. 2 Percentage of raspberry fruit with Botrytis grey mould $(\mathbf{a}, \mathbf{b})$ and healthy fruit $(\mathbf{c}, \mathbf{d})$ for three fruit sources increased and decreased over time in 2007 , respectively. The same batch of fruit (450 per storage regime or fruit source) were assessed 2, 4, 7 and 9 days after storage at different conditions
Percentage fruit with $B$. cinerea
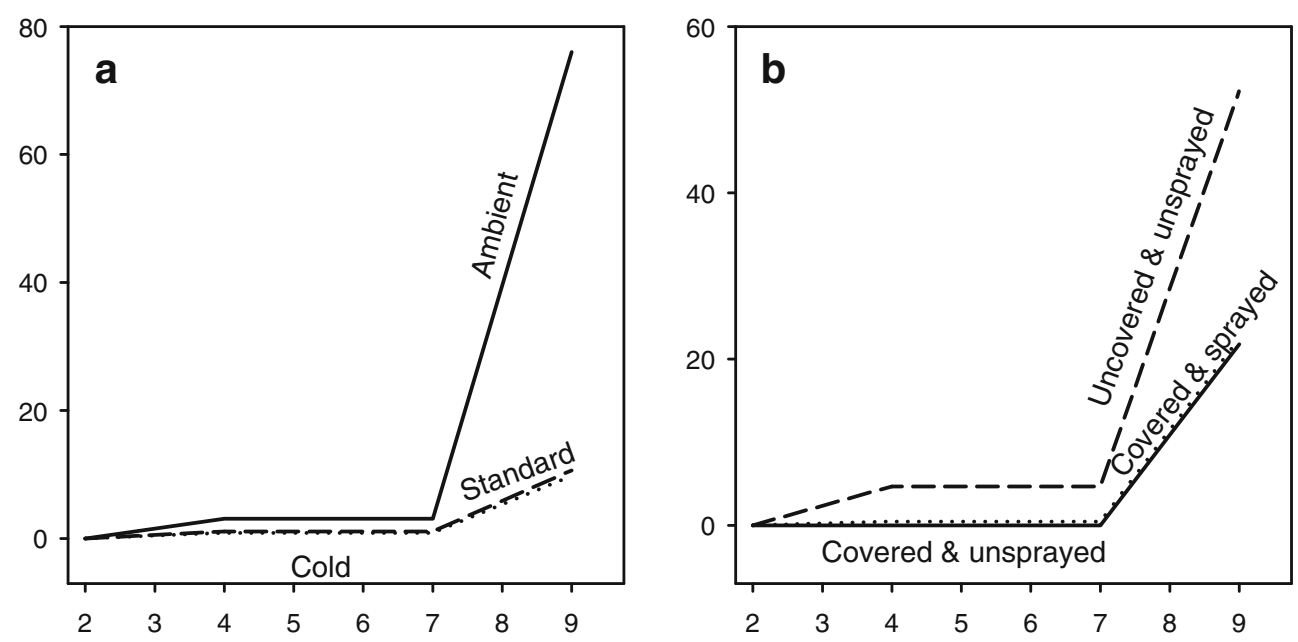

Percentage healthy fruit
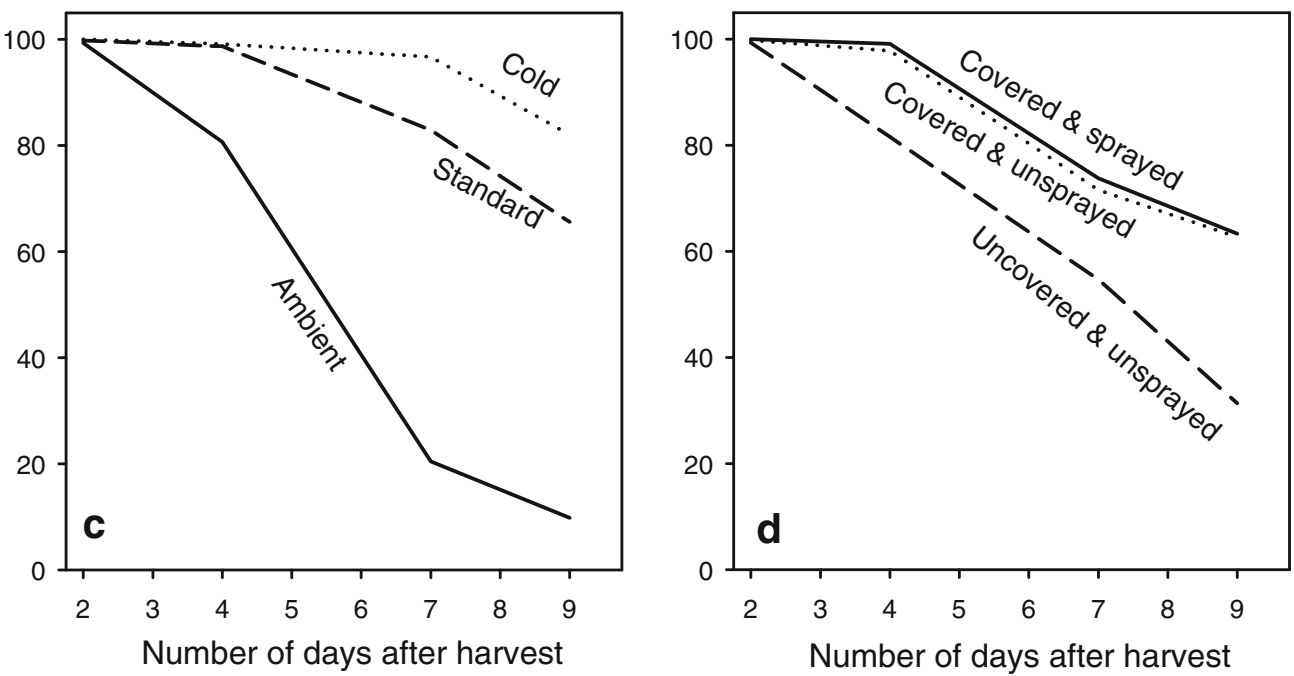

Levels of other fungal rots varied with treatments but generally were at a very low level. There was also no evidence that fruit developing from flowers starting to open around the time of fungicide application had a lower incidence of post-harvest fruit rot than those developing from flowers midway between fungicide sprays (data not presented).

Incidence of grey mould increased from $<1 \%$ on day 4 , to nearly $8 \%$ on day 7 and to nearly $34 \%$ on day 9 . In general, the greatest incidence of grey mould was found in fruit stored at ambient conditions (16.6\%) and least in fruit under prolonged cold storage (3.7\%). Nearly all fruit in storage regime 2 to 5 (Table 1) remained healthy, irrespective of fruit sources, after 7 days. The significant interactions between assessment times and cold store regimes were primarily due to the greatest and least rate of increase in grey mould with time for the ambient and prolonged cold regimes, respectively (Fig. $3 \mathrm{a}$ ). The prolonged cold storage treatment resulted in nearly zero incidence of grey mould at the 7-day assessments. A greater level of grey mould as well as the rate of increase was found in the uncovered and unsprayed crop than the covered (ca. 8-9\%) (Fig. 3b).

Similarly, the proportion of healthy fruit was significantly affected by storage regime, crop source and assessment time as well as by the interactions of assessment time with cold storage regime and crop type. Nevertheless, the trend was opposite to that for grey mould (Fig. 3c, d). The percentage of healthy fruit reduced from $99.7 \%$ on day 2 to $66.5 \%$ on day 9 , with greatest reductions found in storage at ambient conditions and for fruit from the uncovered crop.

\section{1 .32010}

In 2010, very little grey mould was observed on day 6 (about $1.2 \%$ ). Thus, statistical analysis was applied only to data from the day 8 assessment. There were no significant differences between the two cold storage regimes. The 
Fig. 3 Percentage of raspberry fruit with Botrytis grey mould $(\mathbf{a}, \mathbf{b})$ and healthy fruit $(\mathbf{c}, \mathbf{d})$ for three fruit sources increased and decreased over time in 2008 , respectively. The same batch of fruit $(1,500$ fruit per storage regime or for the uncovered and unsprayed crop and 3,000 fruit for the covered crop) were assessed 2, 4, 7 and 9 days after storage at different conditions
Percentage fruit with $B$. cinerea
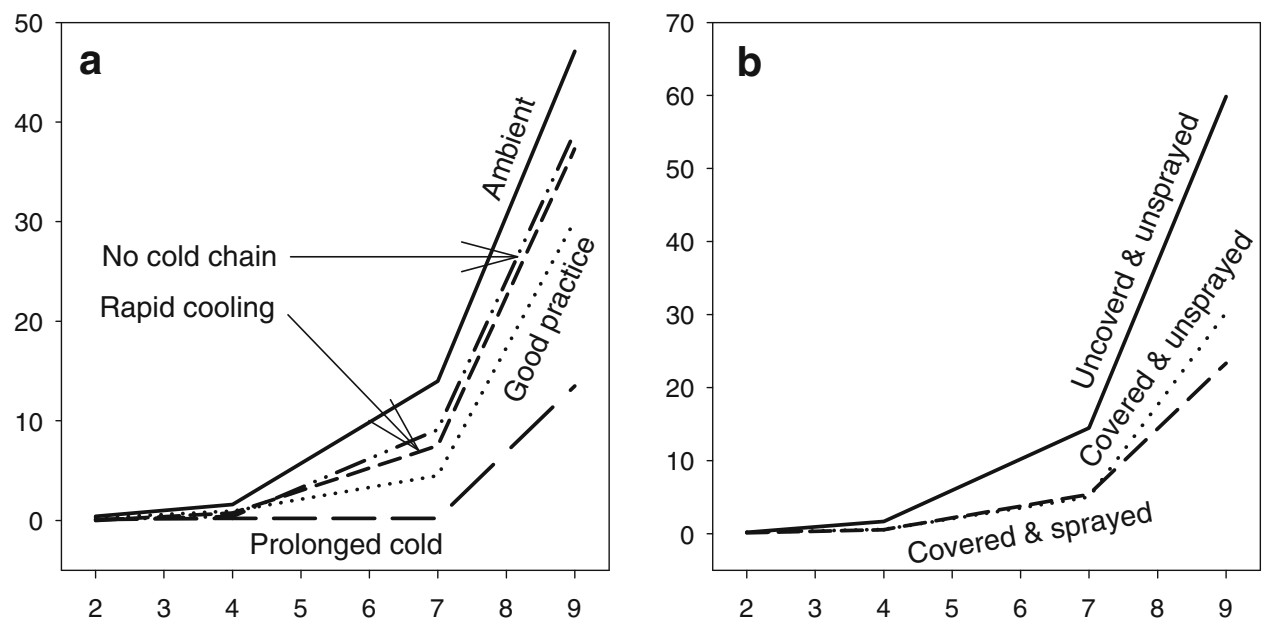

Percentage healthy fruit
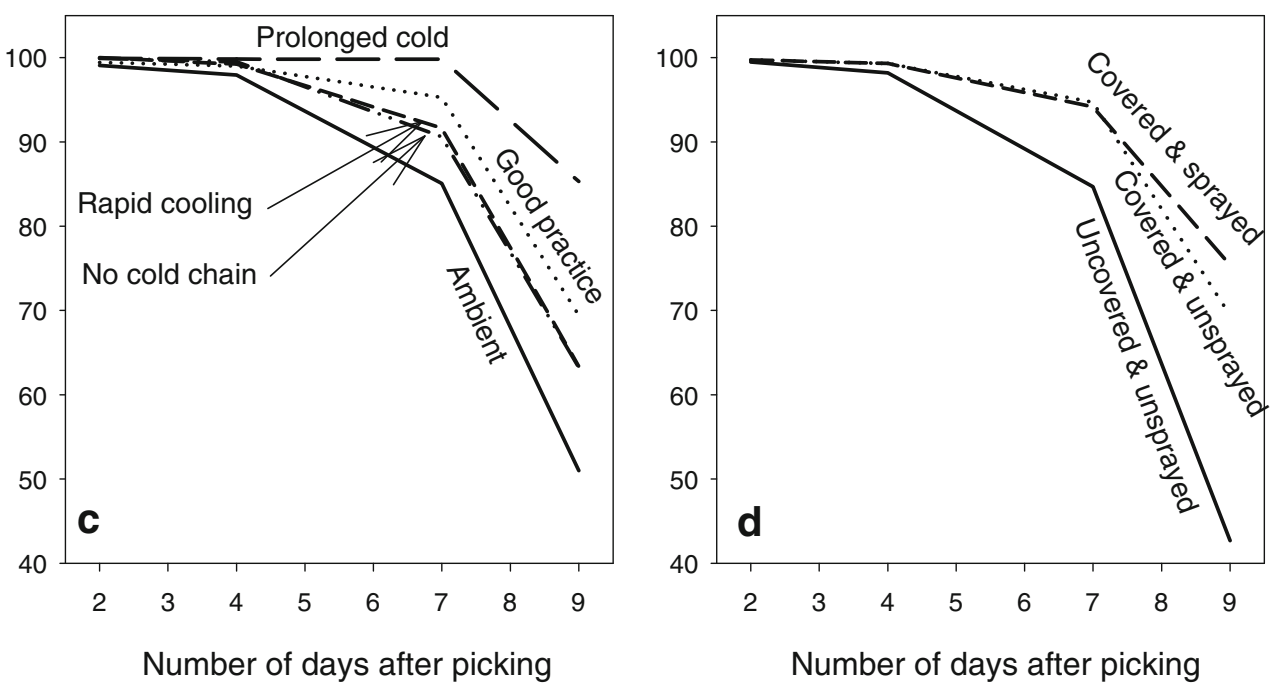

average level of grey mould was $12.2 \%$ and $14.2 \%$ for the cold and standard storage regimes, respectively; the corresponding value for healthy fruit was $65.3 \%$ and $66.4 \%$. There was a considerable amount of fruit rot due to Cladosporium sp. (12.5\%) and Mucor or Rhizopus spp. $(6.2 \%)$, but this was not significantly affected by storage treatments.

\subsubsection{Discussion}

Overall, there was a significant reduction in the incidence of post-harvest grey mould on fruit from tunnel crops, compared with those from outdoor crops when assessed 79 days after the harvest. This reduced risk on crops grown under protection has been demonstrated on other crops such as strawberry (Xiao et al. 2001; Evenhuis and Wanten 2006) and red currant (Creemers et al. 2006), resulting primarily from the protection of flowers and fruit from rainfall. As in our previous study (Xu et al. 2011), there was no fruit with visual grey mould symptoms at harvest but only after several days of storage. In addition to the latent infection that occurred during flowering (McNicol et al. 1985), post-harvest fungal rotting may also have resulted from infection post-harvest by fungal spores deposited on the fruit surface. The spore concentration of $B$. cinerea may be expected to be higher on outdoor crops than on protected crops. Consistent with our previous results (Xu et al. 2011), application of fungicides during the flowering period did not result in much (albeit statistically significant) reduction in the post-harvest incidence of grey mould. The lack of fungicide effects is likely due to the fact that flowers are open continuously over time and as a result a large proportion of flowers may not be protected by the fungicides from fungal infection.

The present results on the beneficial effect of cold storage over the storage at ambient cool conditions in reducing post-harvest raspberry fruit grey mould agree with 
Table 3 Estimated yields (tonnes per hectare) of first class and waste raspberries picked by the farm staff at the two trial sites for the two tunnels, each subjected to one of the two management strategies (conventional and integrated management) in 2009 and 2010

\begin{tabular}{|c|c|c|c|c|c|}
\hline \multirow[t]{2}{*}{ Site } & \multirow[t]{2}{*}{ Year } & \multicolumn{2}{|l|}{ Integrated } & \multicolumn{2}{|c|}{ Conventional } \\
\hline & & 1st class & Waste & 1st class & Waste \\
\hline \multirow[t]{2}{*}{ Kent } & 2009 & 11.4 & 1.4 & 11.9 & 1.2 \\
\hline & 2010 & 8.9 & 1.9 & 8.4 & 1.6 \\
\hline \multirow[t]{2}{*}{ Cambridgeshire } & 2009 & 20.7 & 0.8 & 19.9 & 0.7 \\
\hline & 2010 & 9.4 & 0.4 & 9.8 & 0.4 \\
\hline
\end{tabular}

two previous studies (McNicol et al. 1990; Ellis et al. 2008). Although the rate of development is reduced, $B$. cinerea can continue to grow in cold storage; conidia can germinate and mycelium grow at temperatures from $0^{\circ} \mathrm{C}$ upwards (Jarvis 1980). B. cinerea can grow aggressively at $10^{\circ} \mathrm{C}$, whereas the rate of infection is reduced in fruit stored at $0^{\circ} \mathrm{C}$ immediately after picking, causing reduced development of post-harvest grey mould (Tomkins 1952). This explains why cold storage at $2-3^{\circ} \mathrm{C}$ can only delay the onset of symptom development but not eliminate grey mould.

At present in the UK, fruit are generally cooled and held at $4-5^{\circ} \mathrm{C}$ for up to 3 days and subsequent cool-chain transport and display of fruit is generally around $12-16^{\circ} \mathrm{C}$. Comparing to this standard practice, rapid initially cooling to $2^{\circ} \mathrm{C}$ followed storage for 3 days at $4-5^{\circ} \mathrm{C}$ and 3 days at $17^{\circ} \mathrm{C}$ has significantly delayed the onset of fungal rotting: All fruit were healthy at day 7 . Thus, if fruit have to be stored for a period because of oversupply or other reasons, it is better to keep fruit in cold storage $\left(4-5^{\circ} \mathrm{C}\right.$ or lower $)$ and to minimise the transport and shop display period at temperatures of $12-17^{\circ} \mathrm{C}$. 3.2 Field evaluation of the new strategy for managing grey
mould

\subsubsection{IPDM results}

The estimated total yield and waste were similar between the two management strategies at both sites over the 2 years (Table 3). The yield in 2010 was much less than in 2009, especially for the Cambridgeshire site for unknown reasons (though unlikely due to disease management).

Only a few fruit were rotted on day 6 at both sites in both years; thus, only data from the day 8 assessment are presented (Table 4). Overall, the Kent site had a much higher proportion of post-harvest fruit loss than the Cambridgeshire site: In 2009, nearly $68 \%$ fruit were rotted at the Kent site, compared to $35 \%$ at the Cambridgeshire site, and the corresponding values in 2010 were $73 \%$ and $27 \%$. Most of the loss at the Kent site in 2009 was due to $B$. cinerea: More than $53 \%$ of fruit had grey mould by day 8 , compared to $11 \%$ at the Cambridgeshire site. In contrast, the amount of grey mould was similar at the two sites in 2010 , around $3-4 \%$, but most of the loss at the Kent site in 2010 was due to Cladosporium spp. (nearly 48\%).

There were no significant differences between the two storage regimes or between the two management strategies in the proportion of healthy fruit and fruit with damage (including fungal rotting) post-storage. On average, about $50 \%$ of those fruit stored in the cold regime remained

Table 4 Percentage raspberry fruit with $B$. cinerea and other fungi from commercial crops of cv. Octavia in Cambridge and Kent, UK in 2009 and 2010; crops were grown to one of two management strategies (conventional and integrated management), and fruit were subjected to one of two storage regimes (cold and normal-Table 2)

\begin{tabular}{|c|c|c|c|c|c|c|c|c|c|}
\hline \multirow[t]{3}{*}{ Site and management strategy } & \multirow[t]{3}{*}{ Storage } & \multicolumn{8}{|c|}{ Incidence of affected fruit 8 days after harvest } \\
\hline & & \multicolumn{4}{|l|}{2009} & \multicolumn{4}{|l|}{2010} \\
\hline & & Total fruit & Botrytis & Cladosporium & Penicillium & Total fruit & Botrytis & Cladosporium & Penicillium \\
\hline \multicolumn{10}{|l|}{ Cambridgeshire } \\
\hline \multirow[t]{2}{*}{ Integrated } & Cold & 1,022 & 10 & 16 & 19 & 1,344 & 3 & 0 & 22 \\
\hline & Normal & 1,071 & 13 & 18 & 20 & 1,350 & 2 & 0 & 22 \\
\hline \multirow[t]{2}{*}{ Conventional } & Cold & 1,125 & 10 & 23 & 11 & 1,333 & 4 & 0 & 20 \\
\hline & Normal & 995 & 11 & 25 & 14 & 1,387 & 4 & 0 & 17 \\
\hline \multicolumn{10}{|l|}{ Kent } \\
\hline \multirow[t]{2}{*}{ Integrated } & Cold & 892 & 44 & 20 & 0 & 1,038 & 3 & 55 & 7 \\
\hline & Normal & 888 & 63 & 41 & 0.1 & 1,080 & 6 & 51 & 2 \\
\hline \multirow[t]{2}{*}{ Conventional } & Cold & 888 & 45 & 23 & 0.3 & 1,154 & 3 & 40 & 4 \\
\hline & Normal & 877 & 67 & 33 & 0 & 1,110 & 6 & 44 & 2 \\
\hline
\end{tabular}


healthy on day 8 , compared with $48 \%$ when stored under the standard regime. About $51 \%$ of those fruit from the conventional management programme remained healthy on day 8 , compared with $47 \%$ for the IPDM strategy. There was virtually no difference in the amount of grey mould between the two management strategies: On average, about $18 \%$ of fruit was affected with grey mould for either of the two management strategies. On the other hand, cold storage led to a significant $(P<0.01)$ reduction in grey mould on day 8 over the standard regime: $16 \%$ versus $20 \%$.

Apart from B. cinerea, Cladosporium spp. and Penicillium spp. were the other fungi commonly observed on rotten fruit on day 8 . The former occurred mainly at the Kent site, particularly in 2010 (39\%), whereas the latter occurred mainly at the Cambridge site (18\%). Neither the storage regimes nor the management strategies significantly affected the incidence of Cladosporium sp. rot on day 8 . However, the IPDM strategy appeared to have resulted in a slight increase (ca. 3\%) of Penicillium $\operatorname{rot}(P=0.03)$.

\subsubsection{Discussion}

The present study demonstrated that the performance of the new management strategy in terms of marketable yield and fruit waste is similar to the conventional management programme when scheduled application of fungicides during flowering is used to control grey mould. Postharvest rots of raspberry fruit caused by species of Cladosporium, Penicillium and Mucor are occasional problems in the UK with the severity level varying with season and geographic location (J Allen, unpublished). Currently no fungicides are applied specifically to control these diseases. Cladosporium sp. occurred at a high level at the Kent site in all three trials and at a moderate level at the Cambridge site in the 2009 IPDM trial. The Kent crops were protected with fleece laid over the crop canopy within the tunnel in order to advance cropping. It is likely that a warmer, more humid environment was created that favoured development of Cladosporium; in outdoor crops, the incidence tends to be higher after rainstorms (Ellis et al. 1991). Penicillium sp. developed post-harvest on fruit especially at the Cambridge site. Often Penicillium fruit rot is associated with bruised, damaged or overripe fruit (Ellis et al. 1991), but this was not the case in the present study. The IPDM strategy appeared to result in a slight increase in Penicillium sp. compared with the conventional strategy. Possibly one or more of the fungicides applied to the conventional grown crop also provide some control of Penicillium spp. Further work is required to identify more clearly the factors associated with development of Penicillium and Cladosporium fruit rots on raspberry and to devise strategies for their management without application of fungicides.

\section{Conclusions}

The new strategy for management of grey mould on raspberry grown under protection produced a marketable yield as high as the conventional programme. The incidence of grey mould was also similar between the new and conventional control strategies. Thus, we believe that this new strategy can be adopted by growers relatively easily, provided they have adequate cold storage facilities, to produce fruit with minimal residues, which in the long term may encourage the consumption of raspberry fruit and contribute to sustainable fruit production. Adoption of this new strategy should result in reduced fungicide input and reduced (possibly zero) fungicide residues on fruit, which is a main concern of the public on fresh perishable fruit.

Acknowledgements Funding from Defra, SEERAD, HDC, Marks \& Spencer plc, The Worshipful Company of Fruiterers and the EM Trust for Horticultural Research is gratefully acknowledged. We are also grateful to the growers and soft fruit marketing companies who supported us in the conduct of field experiments. The projects were led by John Place (Place UK) and well supported by Tim Newton (Berry World), Richard Harnden (BerryGarden) and Lindrea Latham (TotalBerry). Marion Regan, Charles Gaskains and Paul Harrold hosted the field experiments on their farms.

\section{References}

Bielenin A (2002) Control of raspberry and blackcurrant diseases by tolylfluanid. Acta Horticulturae 585:331-333

Creemers P, van Laer S, Pitsioudis F, Meesters P (2006) Evaluation of chemical control of Botrytis cinerea in relation to covering red currant shrubs. Agric Conspec Sci 71:115-119

Duncan RA, Stapleton JJ, Leavitt GM (1995) Population dynamics of epiphytic mycoflora and occurrence of bunch rots of wine grapes as influenced by leaf removal. Plant Pathol 44:956965

Ellis M, Converse R, Williams R, Williamson R (eds) (1991) Compendium of raspberry and blackberry diseases and insects. APS, St Paul

Ellis MA, Madden LV, Wright SR, Madden LV, Wilson LL (2008) Efficacy of pre-harvest fungicide applications and cold storage for post-harvest control of botrytis fruit rot (gray mold) on red raspberry. Online. Plant Health Progress. doi:10.1094/PHP-2008-1015-01-RS

English JT, Kaps ML, Moore JF, Hill J, Nakova M (1993) Leaf removal for control of Botrytis bunch rot of wine grapes in the Midwestern United States. Plant Dis 77:1224-1227

Evenhuis A, Wanten P (2006) Effect of polythene tunnels and cultivars on grey mould caused by Botrytis cinerea in organically grown strawberries. Agric Conspec Sci 71:111-114 
Harrison JG, Williamson B (1986) Botrytis spp. on red raspberry: survival in fruits and infection of canes. Trans $\mathrm{Br}$ Mycol Soc $86: 171-173$

Jarvis WR (1962a) The dispersal of spores of Botrytis cinerea Fr. in a raspberry plantation. Trans Br Mycol Soc 45:549-559

Jarvis WR (1962b) The infection of strawberry and raspberry fruits by Botrytis cinerea Fr. Ann Appl Biol 50:569-575

Jarvis WR (1964) The effect of some climatic factors on the incidence of grey mould of strawberry and raspberry fruit. Hortic Res 3:65-71

Jarvis WR (1980) Epidemiology. In: Coley-Smith J, Verhoeff K, Jarvis W (eds) The biology of Botrytis. Academic, London, pp 219-250

Jennings DL, Carmichael E (1975) Resistance to grey mould (Botrytis cinerea Fr) in red raspberry fruits. Hortic Res 14:109 115

Legard DE, Xiao CL, Mertely JC, Chandler CK (2000) Effects of plant spacing and cultivar on incidence of Botrytis fruit rot in annual strawberry. Plant Dis $84: 531-538$

McNicol RJ, Williamson B, Dolan A (1985) Infection of red raspberry styles and carpels by Botrytis cinerea and its possible role in post-harvest grey mould. Ann Appl Biol 106: 49-53

McNicol RJ, Williamson B, Dolan A (1990) Effects of inoculation, wounding and temperature on post-harvest grey mould (Botrytis cinerea) of red raspberry. J Hortic Sci 65:157-165

O'Neill TM, Pettitt TR, McQuilken MP, Hamer PJC (2002) Integrated approaches to control of grey mould (Botrytis cinerea) in greenhouse crops of container-grown ornamentals. In: Proceed- ings of the British Crop Protection Conference 2002-Pests and Diseases 48, pp 213-218

O’Neill T, Berrie AM, Wedgwood E, Allen J, Xu XM (2009) Effect of canopy manipulation on cane and fruit Botrytis in protected raspberry. Commun Agric Appl Biol Sci 74:633-643

Payne RW (ed) (2006) The guide to GenStat ${ }^{\circledR}$ release 9-Part 2: statistics. VSN International, Hemel Hempstead

Tomkins RG (1952) Moulds. In: Bate-Smith EC, Morris T (eds) Food science: a symposium on quality and preservation of foods. Cambridge University Press, New York, pp 171-181

Williamson B, Jennings DL (1986) Common resistance in red raspberry to Botrytis cinerea and Didymella applanata, two pathogens occupying the same ecological niche. Ann Appl Biol 109:581-593

Xiao CL, Chandler CK, Price JF, Duval JR, Mertely JC, Legard DE (2001) Comparison of epidemics of Botrytis fruit rot and powdery mildew of strawberry in large plastic tunnel and field production systems. Plant Dis 85:901-909

$\mathrm{Xu}$ X-M, Harris DC, Berrie AM (2000) Modelling infection of strawberry flowers by Botrytis cinerea using field data. Phytopathology 90:1367-1374

Xu X-M, Wedgwood E, Berrie AM, Allen J, O’Neill TM (2011) Epidemiology of strawberry and raspberry grey mould in open field and under protection. Agron Sustain Dev. doi:10.1007/ s13593-011-0032-2

Zoecklein BW, Wolf TK, Duncan NW, Judge JM, Cook MK (1992) Effects of fruit zone leaf removal on yield, fruit composition, and fruit rot incidence of Chardonnay and white riesling (Vitis vinifera L) grapes. Am J Enol Vitic 43:139-148 